\title{
EFFECT OF SUBSCAPULARIS TEARS ON FUNCTIONAL SCORES OF PATIENTS UNDERGOING ROTATOR CUFF REPAIR
}

\author{
INFLUÊNCIA DA LESÃO DO SUBESCAPULAR NOS ESCORES \\ FUNCIONAIS DE PACIENTES SUBMETIDOS A REPARO \\ DO MANGUITO ROTADOR
}

\author{
Eduardo Angel Malavolta ${ }^{1}$, Verônica Yulin Prieto Chang $^{1}$, Marcello TraballiBozzi Pinto de Castro ${ }^{1}$, Fernando Brandao Andrade-Silva ${ }^{1}$, \\ Jorge Henrique Assunção ${ }^{1}$, Mauro Emilio Conforto Gracitelli ${ }^{1}$, Arnaldo Amado Ferreira Neto ${ }^{1}$
}

1. Universidade de São Paulo, Hospital das Clínicas, Faculdade de Medicina, Instituto de Ortopedia e Traumatologia, Grupo de Ombro e Cotovelo, São Paulo, SP, Brazil.

\begin{abstract}
Objective: To evaluate the influence of partial- and full-thickness upper third subscapularis tendon tears on the functional scores of patients undergoing arthroscopic rotator cuff repair. Methods: Patients who underwent arthroscopic rotator cuff repair were divided into three groups according to the subscapularis tendon condition: intact, partial-thickness tear, or full-thickness upper third tear. Functional scores were compared among groups. Second, the influence of biceps and infraspinatus tears on the scores was tested using multivariate regression analysis. Results: We evaluated 307 shoulders in 297 patients. Full-thickness upper third subscapularis tears presented significantly worse scores than intact tendons. Partial-thickness tears had scores that did not differ significantly from those of the other groups. Patients with full-thickness upper third tears presented a greater rate of injured and unstable biceps tendons. The multivariate analysis showed that biceps and infraspinatus tendon tears did not influence the scores or the intergroup comparison. Conclusion: Full-thickness upper third subscapularis tendon tears presented worse functional scores than intact subscapularis tendons among patients undergoing posterosuperior rotator cuff repair. Patients with full-thickness subscapularis tears were more likely to suffer biceps tears, but this fact did not influence functional scores. Level of Evidence I; Clinical randomized trial
\end{abstract}

Keywords: Rotator cuff, Arthroscopy, Injury

\section{RESUMO}

Objetivo: Avaliar a influência das lesões do terço superior do tendão subescapular nos escores funcionais de pacientes submetidos ao reparo artroscópico do manguito. Métodos: Divisão em três grupos, conforme condição do tendão subescapular: intacto; ruptura de espessura parcial ou ruptura do terço superior de espessura total. Comparamos escores funcionais. Em seguida, a influência das lesões do bíceps e do infraespinhal nos escores foi testada através de análise de regressão multivariada. Resultados: Avaliamos 307 ombros em 297 pacientes. Rupturas subescapulares no terço superior de espessura total apresentaram escores significativamente piores aos pacientes com tendão intacto. Rupturas de espessura parcial apresentaram escore sem diferença significativa em relação aos demais. Pacientes com rupturas do terço superior de espessura total apresentaram maior taxa de lesão e instabilidade tendínea do bíceps. Análise multivariada mostrou que as rupturas tendíneas do bíceps e infraespinal não influenciaram os escores. Conclusão: Pacientes com lesão do terço superior de espessura total do tendão do subescapular apresentaram escores funcionais piores do que pacientes com tendão intacto submetidos ao reparo artroscópico posterossuperior do manguito. Pacientes com rupturas do subescapular com espessura total foram mais propensos a apresentar rupturas do bíceps, sem influenciar escores funcionais. Nível de Evidência l, Estudo clínico randomizado.

Descritores: Manguito Rotador. Artroscopia. Lesão.

Citation: Malavolta EA, Chang VYP, Castro MTBP, Andrade-Silva FB, Assunção JH, Gracitelli MEC, Ferreira Neto AA. Effect of subscapularis tendon tears on scores of patients undergoing arthroscopic repair. Acta Ortop Bras. [online]. 2019;27(2):116-9. Available from URL: http://www.scielo.br/aob.

\section{INTRODUCTION}

Rotator cuff tendinopathy is the main reason to visit a specialized shoulder outpatient clinic, ${ }^{1}$ and $20 \%$ of the population have a tear in these tendons. ${ }^{2}$ The number of surgeries for cuff tear repair is growing ${ }^{3,4}$ causing high economic impacts. ${ }^{5}$ Among the tendons affected, the subscapularis tendon has received less attention in the orthopedic literature. ${ }^{6}$ Around $1 \%$ of all rotator cuff tears affect isolatelly the subscapularis tendon, ${ }^{7,8}$ while more than half of patients with supraspinatus tears also present associated subscapularis tears. ${ }^{9,10}$

The biomechanical importance of the subscapularis tendon has been described. Tears affecting $50 \%$ of the tendon extension result in increased anterior-superior glenohumeral translation. ${ }^{11}$ The chances of pseudoparalysis occurring in massive rotator cuff tears are higher in tears affecting the entire tendon. ${ }^{12}$ Meanwhile, clinical research focusing solely on the evaluation of massive rotator cuff tears has

All authors declare no potential conflict of interest related to this article.

The study was conducted at the Universidade de São Paulo, Hospital das Clínicas do HCFMUSP, Faculdade de Medicina, Instituto de Ortopedia e Traumatologia, Grupo de Ombro e Cotovelo, São Paulo, SP, Brazil.

Correspondence: Fernando Brandao Andrade-Silva. Rua Dr. Ovídio Pires de Campos, 333, 3o andar, Cerqueira Cesar, São Paulo, SP, Brasil. 05403-010. fernando.brandao@hc.fm.usp.br 
not observed any statistical difference between patients with and without subscapularis tears ${ }^{13}$.

The majority of tears affecting the subscapularis, either partial-thickness or full-thickness, involves only the upper third of the tendon. ${ }^{14}$ The clinical repercussions of this type of lesion have not yet been described in the literature. The aim of this this study was to evaluate the influence of an upper third tear of the subscapularis on preoperative functional scores, according to the American Shoulder and Elbow Surgeons (ASES) scale ${ }^{15}$ in patients undergoing arthroscopic posterosuperior rotator cuff repair.

\section{METHODS}

\section{Study Design and Setting}

This was a retrospective cohort study that compared the functional scores of three groups of patients according to the subscapularis tendon characteristics evaluated arthroscopically: intact tendon, partial-thickness tear, or full-thickness upper third tear. The patients included underwent arthroscopy for the treatment of rotator cuff tears from January 2013 to May 2017 and had their shoulder function analyzed one week before surgery according to the American Shoulder and Elbow Surgeons (ASES) scale. All patients had undergone preoperative magnetic resonance imaging (MRI), without the use of intraarticular contrast, in a 1.5T device. Patients with isolated tear of the subscapularis, rotator cuff arthropathy, moderate or severe glenohumeral arthrosis according to Samilson and Prieto, ${ }^{16}$ and previous shoulder surgery were not included.

\section{Variables analyzed}

The following patient-related variables were registered: age, sex, side affected, smoking, diabetes, work-related problems and previous trauma. The tear-related variables included: subscapularis tendon condition (intact, partial-thickness tear, full-thickness upper third tear); supraspinatus and infraspinatus tendons conditions (intact, partial bursal tear, partial articular tear or full-thickness tear); retraction of the supraspinatus and infraspinatus tendons, according to the classification proposed by Boileau et al. ${ }^{17}$ (Stage I - minor retraction; Stage II - moderate retraction; Stage III - severe retraction; Stage IV: massive tear); the long head of the biceps tendon condition and stability; and degree of fatty degeneration of the subscapularis, supraspinatus and infraspinatus muscles, according to Fuchs et al. ${ }^{18}$ All the tear-related variables were determined by arthroscopic inspection, with the exception of muscle fatty degeneration.

The functional evaluations were performed one week before the surgical procedure, according to the ASES scale (0 to 100 points) ${ }^{15}$. This scale includes both a pain component ranging from 0 to 10 points, accounting for $50 \%$ of the overall score, and a functional component based on patient-responses for ten daily living questions, accounting for the other $50 \%$.

\section{Magnetic resonance imaging}

The MRI exams were performed in a 1.5 Tesla Magneto, through a dedicated shoulder coil. The shoulder image acquisition protocol included coronal oblique proton density weighted images (RT/ET, 2,800/38; FOV $14 \mathrm{~cm}$; slice thickness $3.5 \mathrm{~mm}$; interslice gap 0.4 $\mathrm{mm}$; matrix $320 \times 256$ ), axial, oblique coronal and oblique sagittal T2-weighted fat saturated images (RT/ET, 3,400/50; FOV, 14 cm; slice thickness, $3.5 \mathrm{~mm}$; interslice gap $0.4 \mathrm{~mm}$; matrix, $256 \times 256$ ) and oblique sagittal T1-weighted images (RT/ET, 780/15; FOV 14 cm; slice thickness $3.5 \mathrm{~mm}$; interslice gap $0.4 \mathrm{~mm}$; matrix 320 $x$ 256). No intraarticular or intravenous paramagnetic contrast (gadolinium) was used.

\section{Arthroscopy}

The procedures were performed under general anesthesia combined with interscalene block. The patients were placed in the beach chair position, and the conventional portals (posterior, anterior and lateral) were used. With the $30^{\circ}$ arthroscope positioned in the posterior portal, the appearance of the subscapularis tendon was inspected using the lever-push maneuver ${ }^{19}$ in all cases. Through the anterior and anterolateral portals, the tendinous insertion was palpated, using a probe where necessary. In cases where the visualization of the subscapularis was restricted by the biceps tendon, due to instability or partial tear, it was debrided and tenotomized. The other variables described previously were inspected in standardized form.

\section{Statistical analysis}

Continuous variables were tested for normality using the Kolmogorov-Smirnov test, and the homogeneity was evaluated using the Levene test. Continuous variables were presented as means and standard deviation, and the categorical variables as absolute values and percentages. The functional results were compared between the groups using ANOVA with Bonferroni's post-hoc test. Preoperative clinical variables presenting differences with a $p$ value $<0.1$ were analyzed using multivariate regression analysis to test their association with ASES scores, excluding possible confounding factors. The analysis was performed using the software SPSS version 21.0 , with a level of significance of $5 \%$

\section{RESULTS}

We performed 453 rotator cuff repairs during the period analyzed in the study. The following patients were not included in the analysis: open surgeries (54), isolated subscapularis tear (5), reoperations (3), subscapularis tears affecting more than the upper third (40) and those without preoperative clinical information (44). The final cohort comprehended 307 shoulders from 297 patients.

The patient-related variables did not present any difference between the groups (Table 1). Likewise, there were no statistically significant differences regarding the supraspinatus and infraspinatus tears characteristics (Table 2). Patients with a full-thickness subscapularis

\begin{tabular}{c|c|c|c|c|c}
\multicolumn{6}{c|}{ Table 1. Patient-related variables divided according to the study groups. } \\
\hline & $\begin{array}{c}\text { Intact Tendon } \\
(\mathbf{n}=122)\end{array}$ & $\begin{array}{c}\text { Partial Tear } \\
(\mathbf{n}=\mathbf{1 3 1})\end{array}$ & $\begin{array}{c}\text { Full-thickness } \\
\text { tears }(\mathbf{n}=54)\end{array}$ & $\begin{array}{c}\text { Overall } \\
(\mathbf{n}=307)\end{array}$ & $\mathbf{p}$ \\
\hline Age (n sd) & $55,2 \pm 7,9$ & $57,1 \pm 8,7$ & $55,4 \pm 8,5$ & $56,1 \pm 8,4$ & 0,164 \\
\hline Sex [n (\%)] & & & & & \\
\hline Male & $59(48,4)$ & $51(38,9)$ & $18(33,3)$ & $128(41,7)$ & 0,123 \\
\hline Female & $63(51,6)$ & $80(61,1)$ & $36(66,7)$ & $179(58,3)$ & \\
\hline Side [n (\%)] & & & & & \\
\hline Right & $84(68,9)$ & $96(73,3)$ & $40(74,1)$ & $220(71,7)$ & 0,671 \\
\hline Left & $38(31,1)$ & $35(26,7)$ & $14(25,9)$ & $87(28,3)$ & \\
\hline Smoking [n (\%)] & & & & & \\
\hline Smoker & $15(12,3)$ & $21(16,0)$ & $5(9,3)$ & $41(13,4)$ & 0,508 \\
\hline Former smoker & $17(13,9)$ & $19(14,5)$ & $6(11,1)$ & $42(13,7)$ & \\
\hline No & $90(73,8)$ & $91(69,5)$ & $43(79,6)$ & $224(73,0)$ & \\
\hline Diabetes [n (\%)] & & & & & \\
\hline Yes & $18(14,8)$ & $14(10,7)$ & $8(14,8)$ & $40(13,0)$ & 0,575 \\
\hline No & $104(85,2)$ & $117(89,3)$ & $46(85,2)$ & $267(87,0)$ & \\
\hline $\begin{array}{c}\text { Work-related } \\
\text { problems [n (\%)] }\end{array}$ & & & & & \\
\hline Yes & $28(23,0)$ & $20(15,3)$ & $7(13,0)$ & $55(17,9)$ & 0,184 \\
\hline No & $94(77,0)$ & $111(84,7)$ & $47(87,0)$ & $252(82,1)$ & \\
\hline $\begin{array}{c}\text { Traumatic tear } \\
\text { [n (\%)] }\end{array}$ & & & & & \\
\hline Yes & $8(6,6)$ & $8(6,1)$ & $6(11,1)$ & $22(7,2)$ & 0,460 \\
\hline No & $114(93,4)$ & $123(93,9)$ & $48(88,9)$ & $285(92,8)$ & \\
\hline & & & & \\
\hline
\end{tabular}


Table 2. Tear-related variables divided according to the study groups.

\begin{tabular}{|c|c|c|c|c|c|}
\hline & $\begin{array}{l}\text { Intact } \\
\text { tendon } \\
(n=122)\end{array}$ & $\begin{array}{c}\text { Partial } \\
\text { tear } \\
(n=131)\end{array}$ & $\begin{array}{c}\text { Full-thickness } \\
\text { tear } \\
(n=54)\end{array}$ & $\begin{array}{l}\text { Overall } \\
(\mathrm{n}=307)\end{array}$ & $\mathrm{p}$ \\
\hline \multicolumn{6}{|l|}{ Supraspinatus tear } \\
\hline Bursal partial tear & $8(6,6)$ & $9(6,9)$ & $3(5,6)$ & $20(6,5)$ & 0,262 \\
\hline Articular partial tear & $6(4,9)$ & $2(1,5)$ & $2(3,7)$ & $10(3,3)$ & \\
\hline Full-thickness tear & $108(88,5)$ & $120(91,6)$ & $49(90,7)$ & $\begin{array}{c}277 \\
(90,2)\end{array}$ & \\
\hline \multicolumn{6}{|l|}{ Supraspinatus retraction } \\
\hline Stage I & $48(39,3)$ & $48(36,6)$ & $16(29,6)$ & $\begin{array}{c}112 \\
(36,5)\end{array}$ & 0,942 \\
\hline Stage II & $38(31,1)$ & $47(35,9)$ & $22(40,7)$ & $\begin{array}{c}107 \\
(34,9) \\
\end{array}$ & \\
\hline Stage III & $21(17,2)$ & $23(17,6)$ & $11(20,4)$ & $55(17,9)$ & \\
\hline Stage IV & $15(12,3)$ & $13(9,9)$ & $5(9,3)$ & $33(10,7)$ & \\
\hline \multicolumn{6}{|l|}{$\begin{array}{c}\text { Fuchs classification } \\
\text { (supraspinatus) }\end{array}$} \\
\hline I & $100(82,0)$ & $102(77,9)$ & $40(74,1)$ & $\begin{array}{c}242 \\
(78,8) \\
\end{array}$ & 0,566 \\
\hline II & $16(13,1)$ & $21(16,0)$ & $8(14,8)$ & $45(14,7)$ & \\
\hline III & $6(4,9)$ & $8(6,1)$ & $6(11,1)$ & $20(6,5)$ & \\
\hline \multicolumn{6}{|l|}{ Infraspinatus tear } \\
\hline Intact & $101(82,8)$ & $100(76,3)$ & $32(59,3)$ & $\begin{array}{c}233 \\
(75,9)\end{array}$ & 0,063 \\
\hline Bursal partial tear & $0(0,0)$ & $2(1,5)$ & $1(1,9)$ & $3(1,0)$ & \\
\hline Articular partial tear & $4(3,3)$ & $3(2,3)$ & $2(3,7)$ & $9(2,9)$ & \\
\hline Full-thickness tear & $17(13,9)$ & $26(19,8)$ & $19(35,2)$ & $62(20,2)$ & \\
\hline \multicolumn{6}{|l|}{ Infraspinatus retraction } \\
\hline Stage I & $105(86,1)$ & $113(86,3)$ & $41(75,9)$ & $\begin{array}{c}259 \\
(84,4)\end{array}$ & 0,051 \\
\hline Stage II & $10(8,2)$ & $9(6,9)$ & $7(13,0)$ & $26(8,5)$ & \\
\hline Stage III & $7(5,7)$ & $7(5,3)$ & $6(11,1)$ & $10(6,5)$ & \\
\hline Stage IV & $0(0,0)$ & $2(1,5)$ & $0(0,0)$ & $2(0,7)$ & \\
\hline \multicolumn{6}{|l|}{$\begin{array}{c}\text { Fuchs classification } \\
\text { (infraspinatus) }\end{array}$} \\
\hline I & $106(86,9)$ & $107(81,7)$ & $44(81,5)$ & $\begin{array}{c}256 \\
(83,7)\end{array}$ & 0,438 \\
\hline II & $11(9,0)$ & $16(12,2)$ & $9(16,7)$ & $36(11,7)$ & \\
\hline III & $5(4,1)$ & $8(6,1)$ & $1(1,9)$ & $14(4,6)$ & \\
\hline \multicolumn{6}{|l|}{$\begin{array}{c}\text { Longe head of the } \\
\text { biceps tear }\end{array}$} \\
\hline Intact & $77(63,1)$ & $66(50,4)$ & $13(24,1)$ & $\begin{array}{c}156 \\
(50,8)\end{array}$ & $<0,001$ \\
\hline Partial tear $<50 \%$ & $29(23,8)$ & $33(25,2)$ & $17(31,5)$ & $79(25,7)$ & \\
\hline Partial tear > 50\% & $11(9,0)$ & $20(15,3)$ & $13(24,1)$ & $44(14,3)$ & \\
\hline Auto-tenotomized & $5(4,1)$ & $12(9,2)$ & $11(20,4)$ & $28(9,1)$ & \\
\hline \multicolumn{6}{|l|}{$\begin{array}{l}\text { Long head of the } \\
\text { biceps stability }\end{array}$} \\
\hline Stable & $94(77,0)$ & $75(56,5)$ & $11(20,4)$ & $\begin{array}{c}179 \\
(58,3) \\
\end{array}$ & $<0,001$ \\
\hline Unstable & $20(16,4)$ & $31(23,7)$ & $19(35,2)$ & $70(22,8)$ & \\
\hline Dislocated & $3(2,5)$ & $14(10,7)$ & $13(24,1)$ & $30(9,8)$ & \\
\hline Not applicable & $5(4,1)$ & $12(9,2)$ & $11(20,4)$ & $28(9,1)$ & \\
\hline \multicolumn{6}{|l|}{$\begin{array}{c}\text { Fuchs classification } \\
\text { (subscapularis) }\end{array}$} \\
\hline I & $113(92,6)$ & $118(90,1)$ & $49(90,7)$ & $\begin{array}{c}280 \\
(91,2) \\
\end{array}$ & 0,502 \\
\hline$\|$ & $6(4,9)$ & $8(6,1)$ & $5(9,3)$ & $19(6,2)$ & \\
\hline III & $3(2,5)$ & $5(3,8)$ & $0(0,0)$ & $8(2,6)$ & \\
\hline
\end{tabular}

tear presented a greater rate of injured and unstable biceps tendons than patients with an intact or a partial-thickness tear of the subscapularis $(p<0.001)$ (Table 2$)$.

Patients with full-thickness upper third subscapularis tears $(34.2 \pm 19.8)$ presented significantly worse ASES scores than patients with an intact tendon ( $42.3 \pm 18.2 ; p=0.025)$ (Table 3). Patients with a partial-thickness tear presented a $39.8( \pm 18.7)$ mean score, with no statistically significant difference compared to the other groups. The multiple regression analysis included subscapularis tears, infraspinatus tears, and biceps tears as independent variables to test their association with the ASES scores (dependent variable). There were no statistically significant association between infraspinatus and biceps characteristics with functional scores, whereas subscapularis tears were associated with a worse ASES score (Table 4).

\begin{tabular}{c|c}
\multicolumn{2}{c}{ Table 3. Correlation between type of subscapularis tears and ASES scores. } \\
\hline Group & ASES (mean sd) \\
\hline Intact tendon( $n=122)$ & $42,3 \quad 18,2$ \\
\hline Partial tear $(n=131)$ & $39,8 \quad 18,7$ \\
\hline Full-thickness tear $(n=54)$ & $34,2 \quad 19,8$ \\
\hline Overall $(n=307)$ & $39,8 \quad 18,9$ \\
\hline
\end{tabular}

$\mathrm{p}$ Global $=0.030$. Post-hoc Bonferroni's test: Without tears vs Full-thickness tear $p=0.025$. Remainder $p>0.05$

Table 4. Multiple regression analysis for control of confounding factors.

\begin{tabular}{|c|c|c|c|c|}
\hline & & \multicolumn{2}{|c|}{ Confidence interval 95\% } & \\
\hline & Coefficient & Lower & Upper & $p$ \\
\hline Subscapularis tear & $-1,113$ & $-1,929$ & $-0,296$ & 0,008 \\
\hline Long head of the biceps tear & 0,170 & $-0,562$ & 0,902 & 0,648 \\
\hline $\begin{array}{l}\text { Long head of the } \\
\text { bíceps stability }\end{array}$ & $-0,575$ & $-1,348$ & 0,197 & 0,144 \\
\hline Infraspinatus tear & $-0,01$ & $-0,944$ & 0,925 & 0,984 \\
\hline Infraspinatus retraction & 0,569 & $-1,907$ & 3,046 & 0,651 \\
\hline
\end{tabular}

\section{DISCUSSION}

The subscapularis is the largest rotator cuff muscle, and is very important in the balance of forces of the glenohumeral joint. ${ }^{20}$ Despite this fact, it was long neglected in the orthopedic literature, being named "forgotten tendon". ${ }^{20}$ Isolated subscapularis tears are rare, representing $1 \%$ of all tears. ${ }^{7,8}$ However, their presence associated with supraspinatus tear are observed in more than $50 \%$ of arthroscopic rotator cuff repairs. ${ }^{9,10}$ Furukawa et al. ${ }^{14}$ observed subscapularis tear in $69 \%$ of their series, the majority consisting of partial- (35\%) or full-thickness upper third tears (25\%). MRI presents low sensitivity in the detection of these tears, especially in partial-thickness ones, which makes difficult the adequate diagnosis and treatment. ${ }^{10}$ In massive tears, the involvement of more than $50 \%$ of the tendon extension results in poorer function and increases the chance of pseudoparalysis. ${ }^{12}$ However, there is a lack of data in the literature on the clinical impact of the most frequent tears, which affect only the upper portion of the tendon.

Our results demonstrate that patients with a full-thickness upper third tear of the subscapularis present significantly poorer functional results, based on the ASES scale, than patients with an intact tendon. The mean functional scores of patients with full-thickness tears were 8.1 points lower than the scores of patients with intact tendons. Patients with partial-thickness tears of the subscapularis performed worse than patients with intact tendons and better than patients with full-thickness tears, but the differences did not reach statistical significance. In contrast to our findings, Park et al. did not observe any difference in the ASES scores between patients with intact subscapularis tendons (44.4 \pm 20.1$)$, those with involvement of the upper half of the subscapularis $(38.9 \pm 19.7)$ and those with involvement of the entire subscapularis tendon (43.1 \pm 26.7$)$. In comparison to our study, their series included a smaller number of subjects (92 patients) and analyzed only massive rotator cuff tears with pseudoparalysis. Furthermore, their study did not evaluate the influence of partial-thickness tears. To our knowledge, our study is the first to evaluate the influence of upper third subscapularis tendon tears on preoperative functional scores among patients undergoing arthroscopic posterosuperior rotator cuff repair. These data provide further evidence on the clinical relevance of upper third subscapularis tears. 
We should emphasize that the difference of 8.1 points, although statistically significant, did not reach the minimum clinically important difference, which has been found to be 12 points for the ASES scale. ${ }^{21}$ Nevertheless, we could demonstrate that subscapularis tears influenced directly the functional scores of patients presenting baseline impaired scores due to posterosuperior rotator cuff tears. The ASES scale has been used in previous studies analysing subscapularis tears. ${ }^{13,22}$ The scale is the second most widely used for evaluation of rotator cuff tears, and was used in $59 \%$ of studies in journals with greatest impact ${ }^{23}$, presenting high reliability, validity and sensitivity to detect significant clinical differences. ${ }^{24}$ On the other hand, for the analyses of subtypes of rotator cuff tear it may not present sufficient sensitivity. We stress that the ASES scale does not have a specific domain for strength, and even scales that do include this evaluation, such as the Constant-Murley and the UCLA scales, do so only for elevation strength, focusing on the supraspinatus tendon.

The groups compared in this study presented significant differences with regard to the presence of biceps tears. This result was expected, given the anatomical proximity between the upper portion of the subscapularis tendon, the medial pulley, and the long head of the biceps. The association between subscapularis tears and involvement of the biceps tendon has already been described. ${ }^{9,10}$ The lack of association between biceps tears and the ASES scores, found in the multiple regression analysis, excluded the influence of biceps tears as confounding factors in the subscapularis analysis. Similarly, infraspinatus tendon tears, which presented a trend to be higher in patients with full-thickness subscapularis tears, were not associated with the ASES scores, and did not influence the comparison between the groups.
Our study had some limitations. We evaluated only patients in the preoperative period with refractory shoulder pain, and our findings cannot be safely transposed to the population with asymptomatic tears. The groups were unbalanced regarding the rate of injured and unstable biceps tendons, what could have influenced the comparison between the groups. However, multiple regression analysis showed no influence of this variable on functional scores. Although partial-thickness subscapularis tears did not influence functional scores, this study did not evaluate tears evolution and risk factors for tear progression. Therefore, we cannot set specific recommendations on the management of partial tears. The strengths of the study included the novelty of the research, the large casuistic and the use of arthroscopy to define the study groups, considered the gold standard diagnostic method. ${ }^{25}$ Furthermore, the inclusion of only upper third subscapularis tears enhanced the study internal validity. In conclusion, we could demonstrate that the functional scores of patients undergoing posterosuperior rotator cuff repair are directly influenced by the presence of full-thickness upper third subscapularis tears. Additionally, patients with full-thickness subscapularis tears presented a higher rate of biceps tears and biceps instability, but this fact did not influence functional scores. Partial-thickness tears did not affect the clinical results significantly. The clinical relevance of full-thickness upper third subscapularis tears in association with posterosuperior rotator cuff tears was demonstrated, and these data can help surgeons during decision making on the repair of subscapularis tears.

\section{ACKNOWLEDGEMENTS}

Thais Cristina Pereira Vasques, Research Assistant, for her contribution in obtaining the study data.

AUTHORS' CONTRIBUTIONS: Each author made significant individual contributions to this manuscript: EAM (0000-0003-1956-6445)* writing the article, revision of the article, statistical analyses, and performing the surgeries; VYPC (0000-0001-8247-6886)*: participating in the surgeries, acquisition and analysis of the data, and writing the article; MTBPC (0000-0003-2492-848X)*: participating in the surgeries, acquisition and analysis of the data and writing the article; FBAS (0000-0003-3025-1719)*: performing the surgeries, intellectual concept of the article and revision of the article; JHA (0000-0002-2566-3471)* performing the surgeries, intellectual concept of the article and revision of the article; MECG (0000-0002-0214-9576)* performing the surgeries, intellectual concept of the article and revision of the article; AAFN (0000-0001-5097-9542)* intellectual concept of the article and revision of the article. *ORCID (Open Researcher and Contributor ID).

\section{REFERÊNCIAS}

1. Malavolta EA, Gracitelli MEC, Assunção JH, Pinto GMR, Silveira AZF, Ferreira Neto AA. Shoulder disorders in an outpatient clinic: an epidemiological study. Acta Ortop Bras. 2017;25(3):78-80.

2. Yamamoto A, Takagishi K, Osawa T, Yanagawa T, Nakajia D, Shitara H, et al. Prevalence and risk factors of a rotator cuff tear in the general population. $J$ Shoulder Elbow Surg. 2010;19(1):116-20

3. Malavolta EA, Assunção JH, Beraldo RA, et al. Rotator cuff repair in the Brazilian Unified Health System: Brazilian trends from 2003 to 2015. Rev Bras Ortop. 2017;52(4):501-5.

4. Churchill RS, Ghorai JK. Total cost and operating room time comparison of rotator cuff repair techniques at low, intermediate, and high volume centers: mini-open versus all-arthroscopic. J Shoulder Elbow Surg. 2010;19(5):716-21.

5. Pfirrmann CW, Zanetti M, Weishaupt D, Gerber C, Hodler J. Subscapularis tendon tears: detection and grading at MR arthrography. Radiology. 1999;213(3):709-14.

6. Gyftopoulos S, O' Donnell J, Shah NP, Goss J, Babb J, Recht MP. Correlation of MRI with arthroscopy for the evaluation of the subscapularis tendon: a musculoskeletal division's experience. Skeletal Radiol. 2013:42(9):1269-75.

7. Malavolta EA, Assunção JH, Guglielmetti CLB, de Souza FE, Gracitelli ME, Bordalo-Rodrigues M, et al. Accuracy of preoperative MRI in the diagnosis of subscapularis tears. Arch Orthop Trauma Surg. 2016;136(10):1425-30.

8. Su WR, Budoff JE, Luo Z-P. The effect of posterosuperior rotator cuff tears and biceps loading on glenohumeral translation. Arthroscopy. 2010;26(5):578-86.

9. Collin P, Matsumura N, Lädermann A, Denard PJ, Walch G. Relationship between massive chronic rotator cuff tear pattern and loss of active shoulder range of motion. J Shoulder Elbow Surg. 2014;23(8):1195-202.

10. Park JY, Chung SW, Lee SJ, Cho HW, Lee JH, Lee JH, et al. Combined Subscapularis Tears in Massive Posterosuperior Rotator Cuff Tears: Do They Affect Postoperative Shoulder Function and Rotator Cuff Integrity? Am J Sports Med. 2016;44(1):183-90.
11. Furukawa R, Morihara T, Arai $\mathrm{Y}$, Ito H, Kida $\mathrm{Y}$, Sukenari T, et al. Diagnostic accuracy of magnetic resonance imaging for subscapularis tendon tears using radial-slice magnetic resonance images. J Shoulder Elbow Surg. 2014;23(11):e283-90.

12. Richards RR, An KN, Bigliani LU, Friedman RJ, Gartsman GM, Gristina AG, et al. A standardized method for the assessment of shoulder function. J Shoulder Elbow Surg. 1994;3(6):347-52.

13. Samilson RL, Prieto V. Dislocation arthropathy of the shoulder. J Bone Joint Surg Am. 1983;65(4):456-60.

14. Boileau P, Brassart N, Watkinson DJ, Carles M, Hatzidakis AM, Krishnan SG. Arthroscopic repair of full-thickness tears of the supraspinatus: does the tendon really heal? J Bone Joint Surg Am. 2005;87(6):1229-40.

15. Fuchs B, Weishaupt D, Zanetti M, et al. Fatty degeneration of the muscles of the rotator cuff: assessment by computed tomography versus magnetic resonance imaging. J Shoulder Elbow Surg. 1999;8(6):599-605.

16. Burkhart SS, Brady PC. Arthroscopic subscapularis repair: surgical tips and pearls A to Z. Arthroscopy. 2006;22(9):1014-27.

17. Lo IKY, Burkhart SS. Subscapularis Tears: Arthroscopic Repair of the Forgotten Rotator Cuff Tendon. Techniques in Shoulder \& Elbow Surgery. 2002;3(4):282-91.

18. Tashjian RZ, Deloach J, Green A, porucznik CA, Powell AP.. Minimal clinically important differences in ASES and simple shoulder test scores after nonoperative treatment of rotator cuff disease. J Bone Joint Surg Am. 2010;92(2):296-303.

19. Makhni EC, Steinhaus ME, Morrow ZS, Jobin CM, Verma NN, Cole BJ, et al. Outcomes assessment in rotator cuff pathology: what are we measuring? J Shoulder Elbow Surg. 2015;24(12):2008-15.

20. Michener LA, McClure PW, Sennett BJ. American Shoulder and Elbow Surgeons Standardized Shoulder Assessment Form, patient self-report section: reliability, validity, and responsiveness. J Shoulder Elbow Surg. 2002;11(6):587-94. 